\title{
WASH practices and its association with nutritional status of adolescent girls in poverty pockets of eastern India
}

Aparajita Chattopadhyay ${ }^{1}$, Vani Sethi ${ }^{2}$ D, Varsha P. Nagargoje ${ }^{1}$, Abhishek Saraswat ${ }^{1}$, Nikita Surani ${ }^{1}$, Neeraj Agarwal $^{3}$, Vikas Bhatia ${ }^{4}$, Manisha Ruikar ${ }^{5}$, Sourav Bhattacharjee ${ }^{6}$, Rabi N. Parhi', Shivani Dar ${ }^{7}$, Abner Daniel $^{2}$, H. P. S. Sachdev ${ }^{8}$, C. M. Singh ${ }^{3}$, Rajkumar Gope ${ }^{9}$, Vikash Nath ${ }^{9}$, Neha Sareen ${ }^{10}$, Arjan De Wagt ${ }^{2}$ and Sayeed Unisa ${ }^{1 *}$

\begin{abstract}
Background: Water, Sanitation, and Hygiene (WASH) practices may affect the growth and nutritional status among adolescents. Therefore, this paper assesses WASH practices and its association with nutritional status among adolescent girls.

Methods: As a part of an intervention programme, this study is based on baseline cross-sectional data. It was conducted between May 2016-April 2017 in three Indian states (Bihar, Odisha, and Chhattisgarh). From a sample of 6352 adolescent girls, information on WASH practices, accessibility to health services and anthropometric measurements (height, weight and mid upper arm circumference (MUAC)) was collected. Descriptive statistics were used to examine WASH practices, and nutritional status among adolescent girls. Determinants of open defecation and menstrual hygiene were assessed using logistic regression. Association between WASH and nutritional status of adolescent girls was determined using linear regression.

Results: Findings showed $82 \%$ of the adolescent girls were practicing open defecation and $76 \%$ were not using sanitary napkins. Significant predictors of open defecation and non use of sanitary napkin during menstruation were non Hindu households, households with poorer wealth, non availability of water within household premise, non visit to Anganwadi Centre, and non attendance in Kishori group meetings. One-third of adolescent girls were stunted, $17 \%$ were thin and $20 \%$ had MUAC $<19 \mathrm{~cm}$. Poor WASH practices like water facility outside the household premise, unimproved sanitation facility, non use of soap after defecation had significant association with poor nutritional status of adolescent girls.

Conclusions: Concerted convergent actions focusing on the provision of clean water within the household premise, measures to stop open defecation, promotion of hand washing, accessibility of sanitary napkins, poverty alleviation and behavior change are needed. Health, nutrition and livelihood programmes must be interspersed, and adolescents must be encouraged to take part in these programmes.
\end{abstract}

Keywords: Adolescent nutrition, Menstrual hygiene, Open defecation, WASH, Stunting, BMI, MUAC

\footnotetext{
* Correspondence: unisa@iips.net

${ }^{1}$ International Institute for Population Sciences, Mumbai, Maharashtra, India

Full list of author information is available at the end of the article
}

(c) The Author(s). 2019 Open Access This article is distributed under the terms of the Creative Commons Attribution 4.0 International License (http://creativecommons.org/licenses/by/4.0/), which permits unrestricted use, distribution, and reproduction in any medium, provided you give appropriate credit to the original author(s) and the source, provide a link to the Creative Commons license, and indicate if changes were made. The Creative Commons Public Domain Dedication waiver (http://creativecommons.org/publicdomain/zero/1.0/) applies to the data made available in this article, unless otherwise stated. 


\section{Background}

India is a country of 243 million adolescents aged 10 to 19 years [1]. Nutritional status of adolescents is an important health issue because the growth during this period is quicker in an individual's life except infancy. Growths during this phase of life help overall development and provide adequate stores of energy for pregnancy and healthy adulthood. However, the nutrition initiatives in India have been centering on children and women of reproductive age. Few studies provided data on nutritional status of adolescents. In this respect, SWABHIMAAN builds the path to comprehend the situation of adolescents in some selected poor districts of three less developed states in India. The nutritional status of adolescent girls is significantly contributing to the nutritional status of the community [2]. In India, $42 \%$ of adolescent girls aged 15-19 years have Body Mass Index below $18.5 \mathrm{~kg} / \mathrm{m}^{2}$ and $50 \%$ have anemia. Bihar, Chhattisgarh, and Odisha, these three eastern states of India are known to be poverty-stricken pockets. According to the fourth round of National Family Health Survey (NFHS4) 2015-2016, 43.2\% adolescent girls in Bihar, 38.5\% in Chhattisgarh and $37.1 \%$ in Odisha have low BMI [3].

Addressing malnutrition among adolescent girls, especially among the early adolescents could be a window of opportunity for 'catch-up' growth. This subject is also important for breaking the inter-generational cycle of undernutrition. Undernutrition is directly caused by inadequate dietary intake and/or disease and indirectly related to many factors, including poor water, sanitation and hygiene (WASH) [4, 5]. Thus, reducing the burden of malnutrition among adolescents requires a shift from interventions focusing solely on children and infants to those that reach young girls to improve their nutrition as well as the living environment [6].

Currently $\sim 2.3$ billion people still lack even a basic sanitation service and nearly 892 million people still practice open defecation worldwide. Around 844 million people around the globe do not have access to improved drinking water sources [7]. In India, as per the NFHS-4 survey (2015-2016), though 10\% of the household does not have access to an improved source of drinking water, half (52\%) of the household does not use an improved sanitation facility, and $39 \%$ of the household practice open defecation [3]. Three states under present study. i.e., Bihar, Chhattisgarh and Odisha are part of government's Empowered Action Group (EAG) states which lag behingd in demograhic transition and are less developed. In Bihar, Odisha and Chhattisgarh 2, 11, and 9\% households do not have access to an improved source of drinking water and 67, 65 and 59\% of households practice open defecation [3]. Menstrual cleanliness is another important 'hygiene' component. A large number of adolescent girls, especially in rural areas of India and in other countries of Africa and Asia use cloth during menstruation [8-11]. The NFHS-4 (2015-2016) showed that the situation is particularly worse in rural, povertystricken and backward regions of the country compared to urban regions [3]. Multidimensional poverty of India, 2018 reveals, almost 46\% population are living in severe poverty and are deprived in at least half of the dimensions covered in the index that includes nutrition, health, sanitation, drinking water etc. Poor nutrition is the largest contributor to multidimensional poverty. Pockets of poverty are found across India. But there are limited states (Bihar, Jharkhand, Uttar Pradesh, Madhya Pradesh followed by Odisha and Chhattisgarh) with substantial multidimensional poverty pockets. These states accounted more than half of all poor in India. Niti Aayog recently launched the Aspirational Districts programme in (2018) with the aim of fast-tracking the socioeconomic status of districts.

A five-year initiative titled SWABHIMAAN (meaning: Pride) was launched in 2016, layering essential nutrition interventions on adolescent girls and women through the National Rural Livelihoods Mission (NRLM). Poverty reduction and livelihoods generation initiatives of NRLM provide a suitable platform to layer women's nutrition interventions. Such initiatives are tapped by $S W A B H I-$ $M A A N$ in three states of eastern India i.e. Bihar, Odisha and Chhattisgarh that stands at the bottommost positions in different development indices. SWABHIMAAN covers all the stages of a woman's life-cycle with heightened nutritional vulnerability that is adolescence, prepregnancy (newlyweds), pregnancy and lactation (mothers of children under-two) period.

Several studies [12-15] have addressed the effect of WASH interventions on the incidence of various transmissible diseases and on nutritional status amongst children. The $S W A B H I M A A N$ intervention aims at improving nutrition of adolescent girls through formation of adolescent girls' clubs/activation of Sabla clubs, organizing weekly/fortnightly Kishori Sakhi meetings over weekend, providing loans for secondary education of adolescent girls through $\mathrm{VO}$, mobilizing girls for AHD/Kishori Divas services and making efforts to reduce child marriage. The current study is based on the base line data of the intervention project to understand the levels and pure effect of WASH and programme components on nutrition. A Cochrane review of WASH interventions on the nutritional status of children reported small benefits of WASH interventions on growth in children under five years of age [5]. However, studies investigating the impact of WASH practices on measures of physical growth and nutritional sufficiency among adolescents in the Indian context are limited. Therefore, the present study assesses the levels of WASH practices and selected nutritional indices of 
adolescent girls in three tribal pockets of Eastern India. Further it determines the association of WASH and some programme factors on nutritional status of adolescent girls, to guide future interventions.

\section{Methods}

The study is a part of the SWABHIMAAN programme which aimed at improving the nutritional status of adolescent girls, pregnant women, and mothers of children less than two years age in three poverty pockets of India (Bihar, Odisha, and Chhattisgarh) dominated by tribal population. As a part of this programme, primary data amongst adolescent girls (10-19 years) were collected between May 2016 and April 2017 from Purnea district (Jalalgarh and Kasba blocks) of Bihar, Angul district (Pallahara block) and Koraput district (Koraput block) of Odisha and Bastar district (Bakawand and Bastar blocks) of Chhattisgarh. Based on the outcome indicators and the change envisaged, a representative sample of 6352 (Bihar: 1704; Odisha: 1727 and Chhattisgarh: 2921) adolescent girls was drawn using the simple random sampling. Fourty $6 \%$ sample population belongs to scheduled tribe. Data were collected by trained teams, consisting of trained supervisors and field investigators.

A pre-tested, structured, bilingual questionnaire in Bihar and Chhattisgarh (English and Hindi), and Odisha (English and Odia) were used to elicit information on: i) socio-demographic profile, ii) WASH practices (main source of drinking water, accessibility of water facility, type of sanitation facility used, practice of open defecation, use of soap after defecation and use of napkins during mensuration), iii) adolescents' access to health services (accessed health service in last six months, visited Anganwadi (rural child care centre in India), accessed any health services, counselling by a frontline health worker, attended any Kishori (Adolescent girl) group meetings and able to make decision about own healthcare, iv) anthropometric measurements (weight, height and mid upper arm circumference $(\mathrm{MUAC})$ ) were collected using the standard technique [16].

Weight was measured in kilogram (without shoes) using a SECA electronic weighing scale recorded to the nearest $0.1 \mathrm{~kg}$. Height was taken barefooted using stadiometer nearest to $0.1 \mathrm{~cm}$. Mid Upper Arm Circumference was measured in centimeters with a nonstretchable measuring tape nearest to $0.1 \mathrm{~cm}$. The tape was placed firmly but gently on the arm to avoid compression of soft tissue. Quality control checks were conducted for $10 \%$ of the interviewed population. The weighing scales and stadiometer were calibrated on a weekly basis prior to data collection with standard weights $(1,2$ and $5 \mathrm{~kg})$ and a meter $\operatorname{rod}(100 \mathrm{~cm})$. The mean standard errors of measurement for height, weight, and MUAC across all the data collection teams were insignificant and ranged between 0.001-0.025 ( $p<$ $0.10, \mathrm{CI}=-0.004-0.042$ ).

\section{Variables}

Detailed information on dependent and independent variables used in the study is given in this section. Stunting represents the chronic undernutrition that reflects failure to receive adequate nutrition over a long period. Stunting was defined as the height-for-age (HAZ) $\mathrm{z}$-score $<-2 \mathrm{SD}$ and severe stunting as $<-3 \mathrm{SD}$. Thinness was defined as $\mathrm{BMI}<-2 \mathrm{SD}$ and severe thinness as $<-3 \mathrm{SD}$. Body Mass Index is a measure of weight relative to height, and was calculated (weight in $\mathrm{kg} /$ height in $\mathrm{m}^{2}$ ) using WHO growth charts (z-scores) and graded according to WHO classification [17]. The MUAC is the circumference of the left upper arm, measured at the mid-point between the tip of the shoulder and the tip of the elbow and is used for the assessment of nutritional status. Using the data from the SWABHIMAAN baseline survey we estimated MUAC cut-offs for adolescent girls (10-19 years) by calculating Youden's Index. The MUAC value corresponding to the highest value of Youden's Index was chosen as the cut-off. The MUAC cut-offs for adolescents girls (10-19 years) at $<-2$ SD (thinness) and $<-3$ SD (severe thinness) were $<19$ $\mathrm{cm}$ and $<17 \mathrm{~cm}$ respectively.

WHO norms were used to differentiate between improved and unimproved WASH facilities. Improved sanitation facility includes: flush/pour flush, toilet/ latrine and pit latrines (piped sewer system, septic tank, pit latrine, ventilated improved pit/ biogas latrine, pit latrine with slab, twin pit/ composting toilet). The unimproved sanitation facilities include: flush to somewhere else, pit latrine without slab/ open pit, dry/ service latrine and no sanitation facility/ uses open space or field/ jungle. The households with no sanitation facility were considered practicing open defecation as concept of public toilet facility does not exist in rural India. Improved source of drinking water includes: piped water into dwelling/yard/plot, public tap/standpipe, tube well or borehole, protected dug well, protected spring/ rainwater and community reverse osmosis plant. Additionally, whether the water facility was within (also includes water piped into a dwelling/plot/yard) or outside the premise of the household was also included in the analysis. The menstrual practice was considered hygienic if the girl was using locally prepared napkins or sanitary napkins.

The other covariates included in the study were age (10-14 and 15-19 years); religion was divided into two categories, i.e. Hindu and non-Hindu; caste was categorized into Scheduled Caste (SC), Scheduled Tribe (ST), Other Backward Classes (OBC) and others. Five categories constituted the wealth quintile based on series of 
assets i.e. poorest, poor, middle, rich and richest. Covariates like currently attending school, engaged in work outside home and earnings in cash were also included in the dichotomous form (Yes/No).

The variable accessing adolescent health services in past 6 months' denoted girls' participation in Adolescent Health Day. Adolescent Health Day (AHD) is part of a national strategy, Rashtriya Kishor Swasthya Karyakaram (RKSK). The AHD intends to strengthen the adolescent health program and improve preventive services and increase the awareness among adolescents. The variable 'receiving health service/counseling from frontline health worker' indicates receipt of any health and nutrition related advice or counseling from AWW, ANM or ASHA. Anganwadi Centre is a part of ICDS programme that provides basic nutrition and health facilities. The variable 'visiting Anganwadi Centre' includes availing facilities like dry ration or take home ration, health checkup, counseling, sanitary napkins, or medicines. Kishori group is the adolescent girls' club organized by Kishori Sakhi addressing issues specific to adolescent girls using participatory learning and action cycle methodology.

\section{Statistical analysis}

Descriptive statistics were used to examine the characteristics of adolescent girls, their WASH practices, nutritional status, and participation in health and nutrition programmes. The multivariate logistic regression with 95\% confidence interval (CI) was used to determine the predictors of open defecation and menstrual hygiene practices of adolescent girls. In two logistics regressions, considering open defecation and menstrual hygiene as dependent variable, independent variables were sociodemographic factors, WASH facilities, participation in health interventions and programmes. Linear regression was employed to assess the relationship between the nutritional status of adolescent girls and WASH practices. Here, stunting, BMI and MUAC were considered as dependents variables, and WASH facilities and practices, participation in health and nutrition programmes were considered as independent variables. All the analyses were performed using SPSS version 20.

\section{Results}

\section{Characteristics of adolescent girls}

A total of 6352 adolescent girls (Bihar: 1704, Odisha: 1727 and Chhattisgarh: 2921) were included in the study. The socio-demographic characteristics of the adolescent girls were reflective of underprivileged populations. Majority of the adolescent girls were Hindus (82\%) and belonged to the scheduled tribe (54-65\% in Odisha and Chhattisgarh) and other backward classes (68\% in Bihar). Nearly onethird of girls were not attending school and were engaged in work outside the home (Table 1).

\section{WASH practices by adolescent girls and receipt of services}

Overall 93\% of the adolescent girls used an improved source of drinking water. However, a large proportion of girls (96\%) had the water facility outside the household premises. Eighty two percent of them had no sanitation facility in the household, $29 \%$ were not using soap for washing hands after defecation; this proportion was highest in Odisha (37\%) as compared to the other two states. Majority of the girls (77\%) were not using sanitary napkins during menstruation (Table 1 ).

Figure 1 shows the access to water outside household premise practice of open defecation and selected unhygienic practices in the study area. Almost all the households in Bihar had water facility outside the household. Around 83\% households in Chhattisgarh practiced open defecation which is highest among the states under study. Thirty-seven percent households in Odisha did not use soap after defecation and nearly $89 \%$ girls did not use sanitary napkin during menstruation.

Only 9\% of the girls accessed adolescent health services in the last six months preceding the survey and 25\% visited Anganwadi Centre (AWC) for availing any services. Majority of the girls (85\%) had not accessed any service/ counseling from a frontline health worker. Most of them (94\%) reported that they had not attended Kishori group meetings in the past six months. Almost half of the girls reported that they could not make decisions regarding their healthcare (Table 1).

\section{Determinants of open defecation and use of sanitary napkins}

Adolescents from non-Hindu religion (OR: 2.36, 95\% CI 1.87-2.97), who belonged to scheduled caste (OR: 1.34 , CI $0.99-1.83$ ) or scheduled tribe (OR: 1.60 , CI 1.232.08 ), poorer in wealth status (OR: 2.35-4.06, CI 1.955.08), not having access to water within the household premise (OR: 1.73, CI 1.28-2.35), and not visiting AWC for any services (OR: 1.48 , CI 1.24-1.75) were more likely to defecate in open (Table 2). For menstrual hygiene, girls belonging to Hindu religion (OR 3.34, CI 2.37-4.71), with better wealth quintile (OR: 1.31-3.17, CI 0.96-4.30), attending schools (OR 2.19, CI 1.80-2.66), engaged in paid work outside home (OR 0.72, CI 0.58-0.88), able to make decisions about their healthcare (OR: 1.21, CI 1.02-1.45), using improved sanitation facilities (OR: 1.34, CI 1.071.68), and who attended Kishori group meetings (OR 1.57, CI $1.10-2.26)$ were more likely to use sanitary napkins during menstruation (Table 3).

\section{Nutritional status of adolescent girls}

About one-third of the girls were stunted, $17 \%$ had BMI z-score <-2SD (thin), and 20\% had MUAC below $19 \mathrm{~cm}$ (Table 4). Overall, the prevalence of stunting was higher 
Table 1 Percentage of adolescent girls by socio-demographic characteristics, WASH practices, and participation in programmes

\begin{tabular}{|c|c|c|c|c|}
\hline Characteristics & $\begin{array}{l}\text { Bihar } \\
(N=1704)\end{array}$ & $\begin{array}{l}\text { Odisha } \\
(N=1727)\end{array}$ & $\begin{array}{l}\text { Chhattisgarh } \\
(N=2921)\end{array}$ & $\begin{array}{l}\text { Total } \\
(N=6352)\end{array}$ \\
\hline \multicolumn{5}{|l|}{ Age } \\
\hline 10-14 years & 63.2 & 51.2 & 55.5 & 56.4 \\
\hline 15-19years & 36.8 & 48.8 & 44.5 & 43.6 \\
\hline \multicolumn{5}{|l|}{ Religion } \\
\hline Hindu & 41.9 & 95.3 & 98.3 & 82.3 \\
\hline Non-Hindu & 58.1 & 4.7 & 1.7 & 17.7 \\
\hline \multicolumn{5}{|l|}{ Caste } \\
\hline Scheduled Caste (SC) & 19.1 & 15.4 & 2.4 & 10.4 \\
\hline Scheduled Tribe (ST) & 4.9 & 54.1 & 65.1 & 46.0 \\
\hline Other Backward Classes (OBCs) & 68.3 & 22.6 & 27.9 & 37.3 \\
\hline Others & 7.7 & 7.9 & 4.6 & 6.3 \\
\hline \multicolumn{5}{|l|}{ Wealth quintile } \\
\hline Poorest & 6.2 & 32.2 & 21.2 & 20.0 \\
\hline Poor & 13.2 & 23.3 & 21.7 & 20.0 \\
\hline Middle & 24.5 & 16.4 & 19.5 & 20.0 \\
\hline Rich & 31.8 & 15.0 & 16.1 & 20.0 \\
\hline Richest & 24.4 & 13.2 & 21.5 & 20.0 \\
\hline \multicolumn{5}{|l|}{ Currently attending school } \\
\hline Yes & 80.6 & 57.3 & 74.8 & 71.6 \\
\hline No & 19.4 & 42.7 & 25.2 & 28.4 \\
\hline \multicolumn{5}{|l|}{ Engaged in work outside home } \\
\hline Yes & 11.7 & 21.4 & 30.4 & 23.0 \\
\hline No & 88.3 & 78.6 & 69.6 & 77.0 \\
\hline \multicolumn{5}{|l|}{ Earnings in cash ${ }^{\mathrm{a}}$} \\
\hline Yes & 88.9 & 98.3 & 98.9 & 97.4 \\
\hline No & 11.1 & 1.7 & 1.1 & 2.6 \\
\hline \multicolumn{5}{|l|}{ Main source of drinking water } \\
\hline Improved $^{\mathrm{b}}$ & 99.9 & 83.0 & 95.0 & 93.1 \\
\hline Unimproved & 0.1 & 17.0 & 5.0 & 6.9 \\
\hline \multicolumn{5}{|l|}{ Accessibility to water facility } \\
\hline Within premises ${ }^{c}$ & 0.1 & 1.7 & 7.3 & 3.8 \\
\hline Out of premises & 99.9 & 98.3 & 92.7 & 96.2 \\
\hline \multicolumn{5}{|l|}{ Type of sanitation facility used } \\
\hline Improved $^{d}$ & 18.1 & 12.7 & 16.2 & 15.7 \\
\hline Unimproved $^{\mathrm{e}}$ & 81.9 & 87.3 & 83.8 & 84.3 \\
\hline \multicolumn{5}{|l|}{ Practice open defecation ${ }^{f}$} \\
\hline Yes & 79.3 & 83.0 & 83.2 & 82.1 \\
\hline No & 20.7 & 17.0 & 16.8 & 17.9 \\
\hline \multicolumn{5}{|l|}{ Uses soap after defecation } \\
\hline Yes & 72.8 & 63.1 & 74.8 & 71.1 \\
\hline No & 27.2 & 36.9 & 25.2 & 28.9 \\
\hline \multicolumn{5}{|c|}{ Uses sanitary napkin ${ }^{g}$ during menstruation ${ }^{h}$} \\
\hline Yes & 11.2 & 37.4 & 24.8 & 23.3 \\
\hline
\end{tabular}


Table 1 Percentage of adolescent girls by socio-demographic characteristics, WASH practices, and participation in programmes (Continued)

\begin{tabular}{lllll}
\hline Characteristics & $\begin{array}{l}\text { Bihar } \\
(N=1704)\end{array}$ & $\begin{array}{l}\text { Odisha } \\
(N=1727)\end{array}$ & $\begin{array}{l}\text { Chhattisgarh } \\
(N=2921)\end{array}$ & $\begin{array}{l}\text { Total } \\
(N=6352)\end{array}$ \\
\hline No & 88.8 & 62.6 & 75.2 & 76.7
\end{tabular}

Accessed adolescent health services in last six months

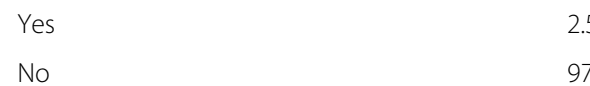

97.5

3.4

96.6

No

Yes

Accessed

Yes

No

Attended any Kishori group meetings

Yes

No

Able to make decision aboutown healthcare

\begin{tabular}{ll} 
Yes & 25.6 \\
No & 74.4 \\
\hline
\end{tabular}

\begin{tabular}{llll}
2.7 & 20.1 & 18.0 & 14.5 \\
97.3 & 79.9 & 82.0 & 85.5 \\
& & & \\
2.1 & 9.0 & 5.9 & 5.7 \\
97.9 & 91.0 & 94.1 & 94.3 \\
& & & \\
25.6 & 62.3 & 36.8 & 40.7 \\
74.4 & 37.7 & 63.2 & 59.3 \\
\hline
\end{tabular}

Note:

ancludes working women (1449) only. Hence sample does not match with total sample (6352)

${ }^{\mathrm{b}}$ Improved source of drinking water as per WHO norm includes piped water into dwelling/yard/plot, public tap/standpipe, tube well or borehole, protected dug well, protected spring, rainwater, and community RO plant

'Water facility within premises includes water piped into a dwelling, plot or yard

dimproved sanitation facility as per WHO norms include flush or pour flush toilet/latrine to: piped sewer system, septic tank, pit latrine, ventilated improved pit

(VIP)/biogas latrine, pit latrine with slab, twin pit/composting toilet

eUnimproved sanitation facilities includes: flush to somewhere else, pit latrine without slab/open pit, dry/service latrine

fOpen defecation represents household that have no sanitation facility and defecate in open spaces or field/jungle

Sanitary napkin refers to a sanitary pad or any locally prepared sanitary napkin

hIncludes menstruating girls (4869) only hence sample does not match total sample (6352)

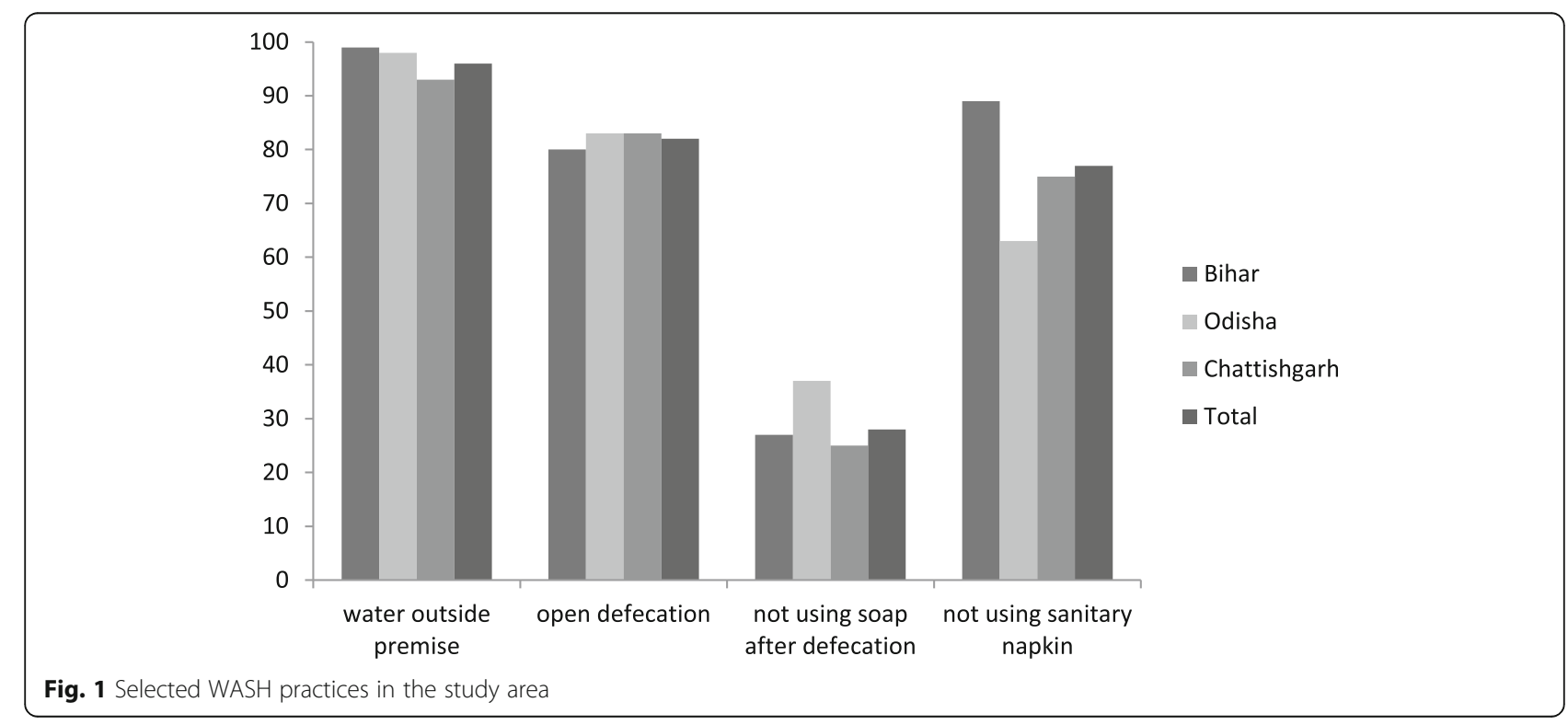


Table 2 Logistic regression showing determinants of open defecation

\begin{tabular}{|c|c|c|}
\hline Characteristics & Odds ratio & $\mathrm{Cl}(95 \%)$ \\
\hline \multicolumn{3}{|l|}{ Socio-demographic } \\
\hline \multicolumn{3}{|l|}{ Religion } \\
\hline \multicolumn{3}{|l|}{$H$ Hindu ${ }^{\oplus}$} \\
\hline Non-Hindu & $2.36^{* * *}$ & $1.87-2.97$ \\
\hline \multicolumn{3}{|l|}{ Caste } \\
\hline Others $^{\circledast}$ & 1.00 & \\
\hline Other Backward Classes (OBCs) & 1.20 & $0.93-1.55$ \\
\hline Scheduled Caste (SC) & $1.34^{*}$ & $0.99-1.83$ \\
\hline Scheduled Tribe (ST) & $1.60^{* * *}$ & $1.23-2.08$ \\
\hline \multicolumn{3}{|l|}{ Wealth quintile } \\
\hline \multicolumn{3}{|l|}{ Richest ${ }^{\circledast}$} \\
\hline Rich & $2.35^{* * *}$ & $1.95-2.84$ \\
\hline Middle & $2.76^{* * *}$ & $2.26-3.37$ \\
\hline Poor & $3.49^{* * *}$ & $2.81-4.32$ \\
\hline Poorest & $4.06^{* * *}$ & $3.25-5.08$ \\
\hline \multicolumn{3}{|l|}{ Currently attending school } \\
\hline \multicolumn{3}{|l|}{$\mathrm{Yes}^{\circledast}$} \\
\hline No & 1.13 & $0.95-1.35$ \\
\hline \multicolumn{3}{|l|}{ Engaged in paid work outside home } \\
\hline \multicolumn{3}{|l|}{$\mathrm{Yes}^{\oplus}$} \\
\hline No & 0.85 & $0.70-1.04$ \\
\hline \multicolumn{3}{|c|}{ Able to make decision aboutown healthcare } \\
\hline \multicolumn{3}{|l|}{$Y_{e s}^{\oplus}$} \\
\hline No & 0.96 & $0.82-1.12$ \\
\hline \multicolumn{3}{|c|}{ WASH Practices and Programme Participation } \\
\hline \multicolumn{3}{|l|}{ Access to water facility } \\
\hline \multicolumn{3}{|l|}{ Within premises ${ }^{\oplus}$} \\
\hline Out of premises & $1.73^{* * *}$ & $1.28-2.35$ \\
\hline
\end{tabular}

Accessed adolescent health services organized by health department Yes $^{\oplus}$
No
1.03
$0.79-1.34$

Visited AnganwadiCentre (AWC) for any service

$$
\mathrm{Yes}^{\circledast}
$$

No

$1.48^{* * *}$

$1.24-1.75$

Accessed any health service or counselling from a frontline health worker

$$
\text { Yes }^{\circledast}
$$

No

0.97

Attended any Kishori group meetings

$$
\text { Yes }{ }^{\circledast}
$$

$1.04 \quad 0.76-1.42$

Note: ${ }^{\otimes}$ - Reference category; Cl confidence interval, ${ }^{* * *} p<0.01,{ }^{*} p<0.10$
Table 3 Logistic regression showing predictors of sanitary napkin use

\begin{tabular}{lll}
\hline Characteristics & Odds ratio & $\mathrm{Cl}(95 \%)$ \\
\hline Socio-demographic & & \\
Religion & & \\
$\quad$ Non-Hindu ${ }^{\oplus}$ & $3.34^{* * *}$ & $2.37-4.71$ \\
Hindu & & \\
Caste & & \\
Scheduled Tribe (ST) & \\
Scheduled Caste (SC) & 0.87 & $0.63-1.19$ \\
Other Backward Classes (OBCs) & 0.85 & $0.68-1.05$ \\
General & 0.95 & $0.65-1.37$ \\
Wealth quintile & & \\
Poorest & & \\
Poor & & $0.96-1.79$ \\
Middle & $1.31^{*}$ & $1.13-2.05$ \\
Rich & $1.52^{* * *}$ & $1.67-3.03$ \\
Richest & $2.25^{* * *}$ & $2.33-4.30$ \\
Currently attending school & $3.17^{* * *}$ & \\
No & & $1.80-2.66$ \\
Yes & & $2.19^{* * *}$
\end{tabular}

Engaged in paid work outside home

$\mathrm{No}^{\circledast}$

Yes

$0.72^{* * *}$

$0.58-0.88$

Able to make decision about own healthcare

$\mathrm{No}^{\oplus}$

Yes

$1.21 * *$

$1.02-1.45$

WASH Practices and Programme Participation

Type of sanitation facility

Unimproved/Open Defecation ${ }^{\text {a® }}$

Improved 1.34** 1.07-1.68

Accessed adolescent health services organized by health department

$\mathrm{No}^{\oplus}$

Yes

0.91

$0.67-1.25$

Visited Anganwadi Centre (AWC) for any service

$\mathrm{No}^{\oplus}$

Yes

1.07

$0.87-1.32$

Accessed any health service or counselling from a frontline health worker

$\mathrm{No}^{\oplus}$

Yes

0.84

$0.65-1.08$

Attended any Kishori group meetings

No ${ }^{\oplus}$

Yes $1.57^{* *} \quad 1.10-2.26$

Note: ${ }^{\ominus}$ - Reference category; Cl confidence interval, ${ }^{* * *} p<0.01,{ }^{* *} p<0.05,{ }^{*} p<0.10$ aln this category majority of the households practiced open defecation (97.8\%) whereas only $2.2 \%$ used unimproved sanitation facilities 
Table 4 Percentage of early (10-14 years) and late (15-19 years) adolescent girls by stunting, BMI, and MUAC

\begin{tabular}{|c|c|c|c|c|c|c|c|c|c|c|c|c|}
\hline & \multicolumn{3}{|l|}{ Bihar } & \multicolumn{3}{|l|}{ Odisha } & \multicolumn{3}{|c|}{ Chhattisgarh } & \multicolumn{3}{|l|}{ Total } \\
\hline & $10-14$ & $15-19$ & $N$ & $10-14$ & $15-19$ & $N$ & $10-14$ & $15-19$ & $\mathrm{~N}$ & $10-14$ & $15-19$ & $\mathrm{~N}$ \\
\hline \multicolumn{13}{|l|}{ Stunting } \\
\hline$<-2 \mathrm{SD}$ & 44.1 & 40.3 & 42.7 & 23.9 & 46.6 & 35.0 & 21.9 & 34.9 & 27.7 & 28.9 & 39.7 & 33.6 \\
\hline$<-3 S D$ & 17.5 & 15.1 & 16.6 & 4.6 & 9.5 & 7.0 & 3.5 & 4.7 & 4.0 & 7.9 & 8.4 & 8.1 \\
\hline$N$ & 1032 & 596 & 1628 & 879 & 839 & 1718 & 1615 & 1300 & 2915 & 3526 & 2735 & 6261 \\
\hline \multicolumn{13}{|l|}{ BMl } \\
\hline$<-2 \mathrm{SD}$ & 27.2 & 26.1 & 26.8 & 16.5 & 8.2 & 12.5 & 17.4 & 10.5 & 14.3 & 20.0 & 13.2 & 17.1 \\
\hline$<-3 S D$ & 7.7 & 6.6 & 7.3 & 3.8 & 1.5 & 2.7 & 3.6 & 1.8 & 2.8 & 4.8 & 2.7 & 3.9 \\
\hline$N$ & 1030 & 593 & 1623 & 879 & 839 & 1718 & 1613 & 1297 & 2910 & 3522 & 2729 & 6251 \\
\hline \multicolumn{13}{|l|}{ MUAC } \\
\hline$<19 \mathrm{~cm}$ & 47.6 & 7.0 & 32.7 & 29.7 & 1.2 & 15.8 & 27.5 & 1.7 & 16.0 & 34.1 & 2.7 & 20.4 \\
\hline$<17 \mathrm{~cm}$ & 20.7 & 2.1 & 13.9 & 7.5 & 0.1 & 3.9 & 5.3 & 0.2 & 3.1 & 10.5 & 0.6 & 6.2 \\
\hline$N$ & 1075 & 625 & 1700 & 879 & 840 & 1719 & 1615 & 1300 & 2915 & 3569 & 2765 & 6334 \\
\hline
\end{tabular}

among late adolescent girls aged 15-19 years. However, low BMI $\left(<18.5 \mathrm{~kg} / \mathrm{m}^{2}\right)$ and MUAC were more prevalent among young adolescent girls aged $10-14$ years. As compared to Chhattisgarh and Odisha, nutritional status of adolescent girls in Bihar was worse; $43 \%$ girls were stunted, 27\% were thin, and 33\% had low MUAC. A difference was found in the observed median height of girls and the WHO standard for median height for each age group (Fig. 2a). The gap in standard and observed median height increased with age. Similarly, there was a considerable gap in the WHO standard median BMI and observed median BMI of girls in each age group (Fig. 2b).

\section{Relationship between WASH and nutritional status}

Water facility outside the household premise had a significant association with stunting and low BMI. Girls who accessed water from outside the household were more likely to be stunted $(p<0.01)$ and were thin $(p<0.10)$, particularly the young adolescent girls $(p<0.05)$. Open defecation had a significant stunting $(p<0.05)$ and low MUAC $(<19 \mathrm{~cm})(p<0.01)$. The girls, not using soap after defecation, were more likely to have low MUAC, especially young adolescent girls $(p<0.01)$. Not attending health services organized by the health department had a considerable negative association with low MUAC $(p<0.10)$. Similarly, non visit to the AWC had a negative impact on BMI and MUAC of older adolescent $(p<0.05)$. Not attending Kishori group meetings was also negatively associated with BMI $(p<0.05)$ and low MUAC $(p<0.01)$ among young adolescent girls aged 10-14 years (Table 5).

\section{Discussion}

The scourge of under-development is confined to certain pockets in India, especially in the central and eastern states where our study area is located. This is seen as an opportunity for backward districts that lack basic amenities, infrastructure, health facilities, etc., to grow. Lack of sanitation, in particular, is strongly correlated with acute malnutrition and stunting (low height for age) [18]. Thus scientific evidence is the need of the hour to strengthen programme implementation. The association between WASH and morbidities has been extensively scrutinized; however, the literature on the interrelationship between WASH and malnutrition provide mixed results. In this context, the paper is a valuable input that explores the nutritional status of the adolescent girls in selected poverty pockets of rural India. It explores basic facilities and practices like drinking water, sanitation facility, hand washing and use of sanitary napkins. Further, it shows the association of WASH practices and programme impacts on adolescent nutrition. This paper examined the inter-relationship between WASH and nutritional status of adolescent girls.

\section{Four important inferences for programme acceleration can be drawn from the results}

Firstly, easy access to water as established in the study is an important determinant to reduce malnutrition amongst adolescents. In the present study, overall 93\% of the adolescent girls used an improved source of water. Similarly, NFHS-4 survey (2015-2016) also reported that $90 \%$ of the household have access to an improved source of drinking water. However, $96 \%$ water facility is available outside household premise. Literature already proved that treatment and safe storage of drinking water in the household reduce the risk of diarrheal disease by $30-40 \%$ [18]. It could be suggested that improved nutritional status amongst adolescent girls could be achieved through continued efforts to deliver an efficient supply of water within the household premise [3]. 
a

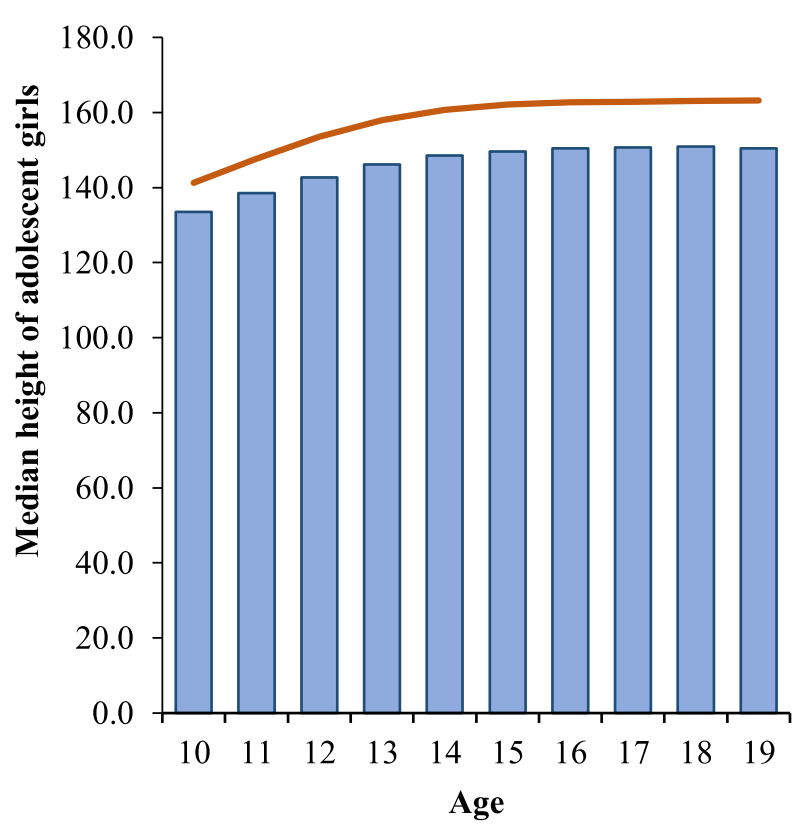

b

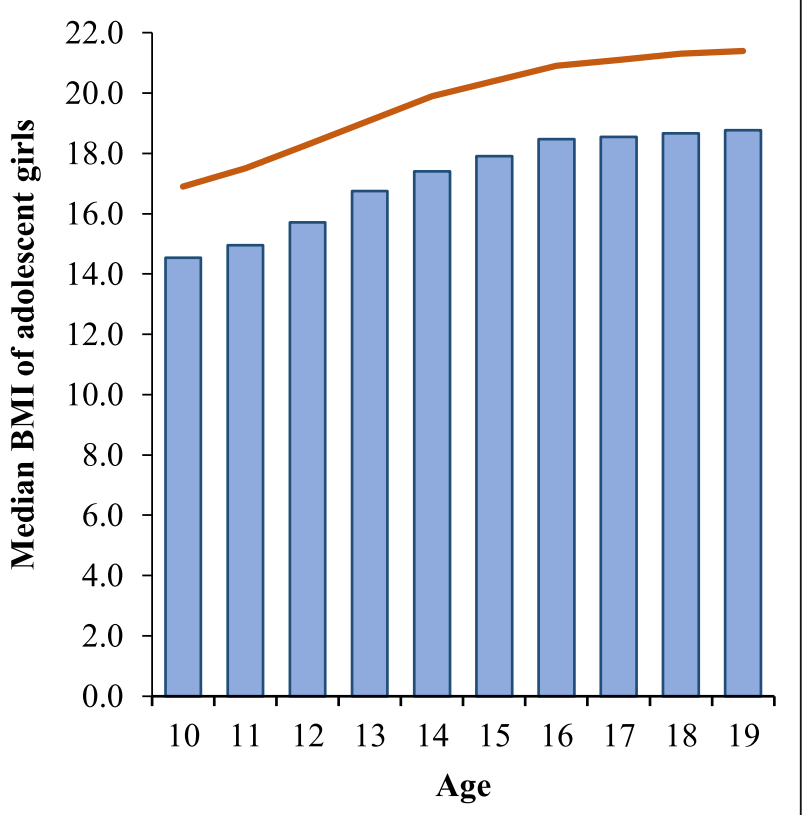

Observed median

WHO standard median

Fig. 2 WHO standard median and observed medians for (a) height and (b) BMI among adolescent girls

Secondly, the findings of the study must be linked to interventions such as the Swachh Bharat (Clean India) Mission to implement evidence-based programme. The focus should also be on strengthening national institutions, fostering strong private sector participation, and enabling behaviour change, rather than merely building toilets. Improved sanitation and personal hygienic practices are crucial for reducing the risks of communicable diseases and improving public health [19]. Open defecation poses a serious threat to the health of children/adolescents in India and especially in the rural areas and poor households. India remains one of the countries with highest rates of open defecation (prominent especially in rural areas), despite the recent growth and poverty reduction; the percentage of such practice is still high compared to rest of the South Asia and the world [7].

Overall in the present study, 82\% (Bihar: 79\%, Odisha: 83\% and Chhattisgarh: $83 \%$ ) of the adolescent girls were practicing open defecation. NFHS-4 survey (2015-2016) reported that $39 \%$ of the household practice open defecation with 67, 65 and 59\% in states of Bihar, Odisha, and Chhattisgarh [3]. Similarly, the National Sample Survey also reported that more than half of India's rural population (52\%) defecates in the open [20]. Diarrheal related deaths amongst adolescents are reported to be amongst the top ten for the age group of 10-19 year and second among the age group of 10-14 year globally [19]. Several studies have documented that open defecation is a significant constraint on growth in South Asia [2125]. Provision of sanitary facility and access to water are fundamental rights that need focused attention.

Thirdly, a policy level concrete decision to universalize the Menstrual Hygiene Scheme (MHS) is much needed. About three fourth of the adolescent girls in our study are not using sanitary napkins. Menstrual Hygiene Management (MHM) is a problem for adolescent girls in low and middle-income countries (LMICs), particularly when attending school [26]. Menstrual cleanliness is a crucial 'hygiene' component. A large number of adolescent girls, especially in rural areas, use cloth during menstruation [10, 11, 27] like many other countries of Africa, South Asia, and West Asia [8, 9, 28]. Cloths are traditionally used to absorb menstrual flow; they are cheaper and create less environmental pollution, but are gradually being replaced by disposable sanitary napkins, particularly in urban areas. Cleaning and drying cloth is a problem if girls lack water, privacy and a drying place $[29,30]$. Such unhygienic practices hinder the proper nutrition and health of girls and are needed to be changed [31]. As revealed in our study, girls who used sanitary napkins were more likely to belong to rich wealth quintile, attended school, and were exposed to Kishori group meetings. In India, as per the MHS 
Table 5 Linear regression showing determining the nutritional status of adolescent girls

\begin{tabular}{|c|c|c|c|c|c|c|c|c|c|}
\hline \multirow[t]{3}{*}{ Variables } & \multicolumn{3}{|l|}{ Stunting } & \multicolumn{3}{|l|}{ BMI } & \multicolumn{3}{|l|}{ MUAC } \\
\hline & \multicolumn{9}{|c|}{ Coefficients } \\
\hline & $10-14$ yrs & $15-19$ yrs & Total & $10-14$ yrs & 15-19yrs & Total & $10-14$ yrs & 15-19yrs & Total \\
\hline \multicolumn{10}{|l|}{ Accessibility to water facility } \\
\hline Within premises ${ }^{\oplus}$ & 1.00 & 1.00 & 1.00 & 1.00 & 1.00 & 1.00 & 1.00 & 1.00 & 1.00 \\
\hline Out of premises & $-0.20^{* *}$ & $-0.16^{*}$ & $-0.19^{* * *}$ & $-0.20^{* *}$ & -0.03 & $-0.14^{*}$ & -0.29 & -0.06 & -0.27 \\
\hline \multicolumn{10}{|l|}{ Households' sanitation facility } \\
\hline Improved $^{\circledast}$ & 1.00 & 1.00 & 1.00 & 1.00 & 1.00 & 1.00 & 1.00 & 1.00 & 1.00 \\
\hline Unimproved/Open Defecation & $-0.10^{*}$ & -0.04 & $-0.08^{* *}$ & 0.01 & 0.02 & 0.02 & $-0.32^{* * *}$ & -0.09 & $-0.28^{* * *}$ \\
\hline \multicolumn{10}{|l|}{ Uses soap after defecation } \\
\hline Yes $^{\oplus}$ & 1.00 & 1.00 & 1.00 & 1.00 & 1.00 & 1.00 & 1.00 & 1.00 & 1.00 \\
\hline No & -0.05 & -0.01 & -0.01 & -0.05 & 0.00 & -0.03 & $-0.26^{* * *}$ & $-0.17^{*}$ & $-0.31^{* * *}$ \\
\hline \multicolumn{10}{|c|}{ Uses sanitary napkin during menstruation } \\
\hline Yes $^{\circledast}$ & NA & 1.00 & NA & NA & 1.00 & NA & NA & 1.00 & NA \\
\hline No & NA & -0.04 & NA & NA & -0.05 & NA & NA & -0.04 & NA \\
\hline \multicolumn{10}{|c|}{ Accessed adolescent health services organized by health department } \\
\hline Yes $^{\oplus}$ & 1.00 & 1.00 & 1.00 & 1.00 & 1.00 & 1.00 & 1.00 & 1.00 & 1.00 \\
\hline No & 0.08 & 0.05 & 0.08 & -0.03 & 0.08 & 0.01 & -0.29 & -0.03 & $-0.26^{*}$ \\
\hline \multicolumn{10}{|c|}{ Visited AnganwadiCentre (AWC) for any service } \\
\hline Yes $^{\oplus}$ & 1.00 & 1.00 & 1.00 & 1.00 & 1.00 & 1.00 & 1.00 & 1.00 & 1.00 \\
\hline No & -0.08 & -0.03 & -0.01 & -0.08 & $-0.09^{* *}$ & $-0.08^{* *}$ & $-0.52^{* * *}$ & $-0.20^{* *}$ & $-0.66^{* * *}$ \\
\hline \multicolumn{10}{|c|}{ Accessed any health service/counselling from a frontline health worker } \\
\hline Yes $^{\oplus}$ & 1.00 & 1.00 & 1.00 & 1.00 & 1.00 & 1.00 & 1.00 & 1.00 & 1.00 \\
\hline No & 0.06 & 0.06 & 0.06 & 0.09 & 0.05 & 0.08 & 0.33 & 0.18 & 0.30 \\
\hline \multicolumn{10}{|l|}{ Attended any Kishori group meetings } \\
\hline Yes $^{\oplus}$ & 1.00 & 1.00 & 1.00 & 1.00 & 1.00 & 1.00 & 1.00 & 1.00 & 1.00 \\
\hline No & 0.02 & -0.04 & 0.01 & $-0.22^{* *}$ & -0.00 & -0.09 & $-0.62^{* * *}$ & -0.07 & $-0.40^{* *}$ \\
\hline
\end{tabular}

Note: ${ }^{\oplus}$ - Reference category; ${ }^{* * *} p<0.01,{ }^{* *} p<0.05,{ }^{*} p<0.1$

implemented in some states, sanitary napkins are made available to rural adolescent girls through the ASHA worker [32]. Hence, the issue of cost and access to sanitary napkins seems to be unjustifiable; however, further research is needed on quality and distribution of napkins supplied by ASHA. Concentrated efforts are required to improve information, education, and communication (IEC) activities around the same at available platforms, like schools, AWCs, or through ASHA. During these IEC sessions, adolescent girls also need to be informed about the safe and hygienic sanitary practices and associated health outcomes. Apart from education, awareness, resources and the freedom to choose what material the girls want to use, availability of sanitation facilities, and water availability within premise are a critical area to consider while evaluating sanitary napkin use.

Fourth, our study established that WASH practices have a significant association with the nutritional status of adolescent girls (girls who accessed water from outside, used unimproved sanitation facility and were not using soap after defecation were more likely to be stunted, thin and had low MUAC $(<19 \mathrm{~cm}))$. Supporting these findings, many studies have shown that access to water [33, 34] and proper sanitation and hygiene [25, 35] have a significant association with nutritional status of adolescent girls, even after controlling all other vital factors like disease and food intake. Thus, programmes for WASH need to be strengthened, especially in low resource settings. Convergence between health, nutrition, and WASH is requiredto address the problem of malnutrition comprehensively. During community health campaigns and door to door health visits, promoting both improved nutrition and WASH practices will save resources. Positive nutritional outcomes are dependent on WASH interventions and nutrition actions. In the present study, about one-third of adolescent girls were stunted, $17 \%$ were thin and $20 \%$ had MUAC $<19 \mathrm{~cm}$. Several studies have reported a high prevalence of stunting and thinness amongst adolescent girls [23-25]. 
Observational studies have found associations between the frequency of open defecation and prevalence of stunting [4]. An analysis of several demographic and health surveys (DHS) in 65 countries reported that open defecation explains over half of the variation in average child height between countries [36]. Another analysis of 171 surveys in 70 LMICs found that increasing access to and use of improved sanitation and improved water sources reduced the risk of stunting [37]. Poor WASH conditions leads to additional burden of undernutrition. The present study found that poor WASH practices (water facility outside the premise, unimproved sanitation facility, not using soap after defecation) and nonparticipation in health and nutrition services had a significant association with nutritional status of adolescent girls. Similarly, studies reported that lack of drinking water availability in household, poor sanitation and personal hygiene, was significantly associated with high morbidities and poor nutritional status of adolescent $[23,25,38,39]$. Overall poor WASH practices are identified as a salient factor in determining the overall nutritional status of adolescents [21, 40, 41].

The strength of the present study is that it is a community based survey, conducted on a plausibly large sample size with good quality control and monitoring. The sample was systematically drawn from deprived rural areas which are hotspots for programmes and interventions aimed at improving nutrition. Also, studies on WASH practices and nutritional status of adolescent girls' aged 10-19 years are rare in India. However, there are also a few caveats, because of the cross-sectional nature of the study, conclusions related to cause and effect cannot be drawn. Also, sample being selected only from three geographical areas is another limiting factor, restricting the generalisability of the results.

\section{Limitations}

We acknowledge that the study is in the half way mark from its larger project objectives. It is based on the baseline survey of an intervention study that is yet to estimate the effects of its intervention. Intermittent data is not available to measure the impact of series of programmes that the project has aimed for. Further, in our analysis, we did not include all known factors that explain health of an adolescent like food intake, disease incidence, health facility availability and utilization, functioning of public distribution etc. due to data limitation. The aim here is to understand pure effect of WASH and selected programme on adolescent health from programmatic point of view. In a large scale survey, it is also difficult to quantify social taboos, quality of toilets, cultural practices, quality and quantity of food availability through public distribution, intra household resource distribution, economic and social inequality, etc. that also determine nutritional health of a young girl. Further, as all the adolescent girls were unmarried, the survey questions did not emphasize the reproductive health aspects of these girls, considering the sociocultural taboos in rural India.

\section{Conclusions}

WASH practices have a significant association with the nutritional status of adolescent girls. Therefore, there is a need to spread awareness among people in low resource settings regarding the assocation of poor WASH practices and poor nutritional status. From a programmatic point of view, policies related to economic empowerment and health must be strengthened, encouraging visits to the AWC through Anganwadi worker/ ASHAs, encouraging adolescent girls to attend Kishori Diwas by creating awareness in the community, and emphasizing focused efforts on improving education through strategies such as Beti Bachao, Beti Padhao (Save girl child, educate a girl child). Convergence between health, nutrition, and WASH can expansively and inclusively address malnutrition. National Rural Livelihoods Mission (NRLM) also needs to extend services to adolescent girls who are the future mothers.

Moreover, programmes for WASH need to be strengthened, especially in low resource settings. Realization of rights of poor and marginalized people for sufficient clean water also requires utmost attention. Through the National Rural Health Mission (NRHM), the government of India has been trying to reach out to women/girls with low cost branded sanitary napkins. Ministry of Women and Child Development (MoWCD) is also running SABLA programme to improve their nutrition, health status and health knowledge that includes awareness about health, hygiene, nutrition. Demand generation through community mobilization and system strengthening for efficient supply of water, sanitation, hygienic products, and awareness generation are to be realized as a sustainable solution to reduce the burden of undernutrition among adolescent girls.

\section{Abbreviations \\ AHD: Adolescent Health Day; AllMS: All India Institute of medical sciences; AWC: Anganwadi centre; BMl: Body mass index; Cl: Confidence interval; CTRI: Clinical trial registry of India; DHS: Demographic and health surveys; HAZ: Height for age; ICMR: Indian council of medical research; IEC: Information education and communication; LMIC: Low middle income countries; MHM: Menstrual hygiene management; MHS: Menstrual hygiene scheme; MoWCD: Ministry of women and child development; MUAC: Mid upper arm circumference; NFHS: National family health survey; NRHM: National rural health mission; NRLM: National rural livelihoods mission; OR: Odds ratio; VO: Village Organisations; WASH: Water sanitation and hygiene; WHO: 'World Health Organization}

\section{Acknowledgements}

The authors are grateful to Avinbash Lumba, Anoop Jha, Sonali Sinha for their valuable expertise during the study. Thanks very much to the reviewers and editorial board for their valuable comments. 


\section{Authors' contributions}

VS and SU were involved in the design of the baseline survey. NA, VB, MR, $\mathrm{SB}, \mathrm{SD}, \mathrm{RNP}, \mathrm{RG}, \mathrm{AC}, \mathrm{VPN}$ and CMS led survey implementation teams in Bihar, Odisha and Chhattisgarh. AS, NS, SU HPS, AD, VS and ADW helped in survey execution and management. AC and VPN undertook the analysis. AC, NS made the write up. AC and VPN finalized the paper considering the reviewer's and Editor's comments. All authors read and approved the final manuscript.

\section{Funding}

UNICEF, New Delhi, India.

\section{Availability of data and materials}

The datasets used and/or analysed during the current study are available from the corresponding author on reasonable request.

\section{Ethics approval and consent to participate}

The study has been registered with the Registry for International Development Impact Evaluations (RIDIE-STUDY-ID-58261b2f46876) and Indian Council of Medical Research (ICMR) National Clinical Trials Registry of India (CTRI/2016/11/007482) [42]. Ethical approval was obtained from the Institutional Ethics Committees of All India Institute of Medical Sciences (AllMS) Bihar, Odisha and Chhattisgarh. Verbal consent as approved by the ethical committee was obtained from parents/guardians of each respondent and also from the respondent before administering the questionnaire. As the study implementation was done in rural parts of India, where the selected districts are mostly inhabited by illiterate population, only verbal consent was taken into account. Utmost confidentiality of information and anonymity of respondents was ensured.

\section{Consent for publication}

Not applicable.

\section{Competing interests}

The author declares that he has no competing interests.

\section{Author details}

${ }^{1}$ International Institute for Population Sciences, Mumbai, Maharashtra, India. ${ }^{2}$ Nutrition Section, UNICEF India Country Office, 73 Lodhi Estate, New Delhi, India. ${ }^{3}$ All India Institute of Medical Sciences (AllMS), Patna, India. ${ }^{4}$ All India Institute of Medical Sciences (AllMS), Bhubaneswar, India. ${ }^{5}$ All India Institute of Medical Sciences (AllMS), Raipur, India. ${ }^{6}$ UNICEF India, Field Office Odisha, Bhubaneswar, India. ' UNICEF India, Field Office Bihar, Patna, India. ${ }^{8}$ Sitaram Bhartia Institute of Science and Research, New Delhi, India. ${ }^{9}$ Ekjut, Chakradharpur, Jharkhand, India. ${ }^{10}$ Independent Consultant, New Delhi, India.

Received: 14 November 2018 Accepted: 24 June 2019

Published online: 05 July 2019

\section{References}

1. Office of the Registrar General and Census Commissioner. Census of India. C-series/ C-14 five year age group data by residence and sex. New Delhi: Ministry of Home Affairs, Government of India; 2011.

2. Anand D, Anuradha RK. Malnutrition status of adolescent girls in India: a need for the hour. Int J Sci Res. 2016;5:642-6.

3. International Institute for Population Sciences (IIPS) and ICF. National Family Health Survey (NFHS 4), 2015-16, Mumbai: IIPS. 2017. http://rchiips.org/ NFHS/NFHS-4Reports/India.pdf

4. WHO, UNICEF, USAID. Improving nutrition outcomes with better water, sanitation and hygiene. Practical solutions for policies and programme. Geneva: WHO; 2015. https:/www.unicef.org/media/files/ IntegratingWASHandNut_WHO_UNICEF_USAID_Nov2015.pdf

5. Dangour AD, Watson L, Cumming O, Boisson S, Che Y, Velleman Y, Cavill S, Allen E, Uauy R. Interventions to improve water quality and supply, sanitation and hygiene practices, and their effects on the nutritional status of children. Cochrane Database of Syst Rev. 2013; 8. Art. No.: CD009382. https://doi.org/10.1002/14651858.CD009382.pub2.

6. Danaei G, Andrews KG, Sudfeld CR, Fink G, McCoy DC, Peet E, Sania A, Fawzi MCS, Ezzati M, Fawzi WW. Risk factors for childhood stunting in 137 developing countries: a comparative risk assessment analysis at global, regional, and country levels. PLoS Med. 2016;13(11):e1002164.
7. World Health Organization and United Nation Children Fund. Progress on drinking water, sanitation and hygiene: 2017 update and SDG baselines. Gevena: WHO and UNICEF; 2017. https://www.unicef.org/publications/ index_96611.html

8. Khanna A, Goyal RS, Bhawsar R. Menstrual practices and reproductive problems: a study of adolescent girls in Rajasthan. J Health Manag. 2005; 7(1):91-107.

9. Adinma ED, Adinma JI. Perceptions and practices on menstruation amongst Nigerian secondary school girls. Afr J Reprod Health. 2008;12(1):74-83.

10. Dasgupta A, Sarkar M. Menstrual hygiene: how hygienic is the adolescent girl? Indian J Community Med. 2008;33(2):77-80.

11. Venkatraman CM, Patel SV. Mapping the knowledge and understanding of menarche, menstrual hygiene and menstrual health among adolescent girls in low- and middle-income countries. Reprod Health. 2017;14(1):30.

12. Esrey SA, Potash JB, Roberts L, Shiff C. Effects of improved water supply and sanitation on ascariasis, diarrhoea, dracunculiasis, hookworm infection, schistosomiasis, and trachoma. Bull World Health Organ. 1991;69(5):609.

13. Bartram J, Lewis K, Lenton R, Wright A. Focusing on improved water and sanitation for health. Lancet. 2005;365(9461):810-2.

14. Fewtrell L, Kaufmann RB, Kay D, Enanoria W, Haller L, Colford JM Jr. Water, sanitation, and hygiene interventions to reduce diarrhoea in less developed countries: a systematic review and meta-analysis. Lancet Infect Dis. 2005; 5(1):42-52.

15. Montgomery MA, Elimelech M. Water and sanitation in developing countries: including health in the equation. Environ Sci Technol. 2007:41(1): $17-24$.

16. World Health Organization. Physical status: the use and interpretation of anthropometry. Technical report series, no 854. Geneva: WHO; 1995. http:// apps.who.int/iris/bitstream/handle/10665/37003/WHO_TRS_854.pdf; jsessionid=BE4647CB9345760A6A776FF771 C49A1B?sequence=1

17. World Health Organization. WHO growth reference for adolescents. Geneva: WHO; 2007. http://www.who.int/growthref/who2007_bmi_for_age/en/

18. USAID. WASH and Nutrition. Water and Development strategy, Implementation Brief. 2015. https://www.usaid.gov/sites/default/files/ documents/1865/WASH_Nutrition_Implementation_Brief_Jan_2015.pdf

19. Thakadu OT, Ngwenya BN, Phaladze NA, Bolaane B. Sanitation and hygiene practices among primary school learners in Ngamil and district, Botswana. Phys Chem Earth. 2018;105:224-30.

20. National Sample Survey Office. Swachhta Status Report. New Delhi: Ministry of Statistics and Programme Implementation, government of India; 2016. http://mospi.nic.in/sites/default/files/publication_reports/Swachhta_Status_ Report\%202016_17apr17.pdf

21. Lin A, Arnold BF, Afreen S, Goto R, Huda TMN, Haque R, Raqib R, Unicomb L, Ahmed T, Colford JM, et al. Household environmental conditions are associated with enteropathy and impaired growth in rural Bangladesh. Am Soc Trop Med Hyg. 2013;89(1):130-7.

22. Ghosh A, Gupta A, Spears D. Are children in West Bengal shorter than children in Bangladesh? Econ Polit Wkly. 2014;48(8):21-4.

23. Rah JH, Cronin AA, Badgaiyan B, Aguayo VM, Coates S, Ahmed S. Household sanitation and personal hygiene practices are associated with child stunting in rural India: a cross-sectional analysis of surveys. BMJ Open. 2015;5(2): e005180.

24. Pal A, Pari AK, Sinha A, Dhara PC. Prevalence of undernutrition and associated factors: a cross-sectional study among rural adolescents in West Bengal, India. Int J Pediatr Adolesc Med. 2017:4(1):9-18.

25. Pal J, Pal AK. How personal hygiene predicts nutritional status and morbidity profile? A school based study among adolescent girls in a slum area of Kolkata. J Med Sci Clin Res. 2017;5(7):24693-9.

26. Eijk AMV, Sivakami M, Thakkar MB, Bauman A, Laserson KF, Coates S, Howard PAP. Menstrual hygiene management among adolescent girls in India: a systematic review and meta-analysis. BMJ Open. 2016;6(3):e010290.

27. Garg R, Goyal S, Gupta S. India moves towards menstrual hygiene: subsidized sanitary napkins for rural adolescent girls-issues and challenges. Matern Child Health J. 2012;16(4):767-74.

28. Demba E, Morison L, Loeff MSV, Awasana AA, Gooding E, Bailey R, Mayaud $P$, West B. Bacterial vaginosis, vaginal flora patterns and vaginal hygiene practices in patients presenting with vaginal discharge syndrome in the Gambia, West Africa. BMC Infect Dis. 2005;5(1):12.

29. Narayan KA, Srinivasa DK, Pelto PJ, Veerammal S. Puberty rituals reproductive knowledge and health of adolescent schoolgirls in South India. Asia Pacific Popul J. 2001;16(2):225-38. 
30. Yasmin S, Manna N, Mallik S, Ahmed A, Paria B. Menstrual hygiene among adolescent school students: an indepth cross-sectional study in an urban community of West Bengal, India. IOSR J Dent Med Sci. 2013;5(6):22-6.

31. Brocklehurst C, Bartram J. Swimming upstream: why sanitation, hygiene and water are so important to mothers and their daughters. Bull World Health Organ. 2010;88(7):482.

32. Ministry of Health and Family Welfare. National Health Mission, Menstrual Hygiene Scheme: Background. New Delhi: Ministry of Health and Family Welfare, Government of India; 2016. http://www.nhm.gov.in/images/pdf/ programmes/mhs/Guidelines/Revised_Guidelines_for_Menstrual_Hygiene_ Scheme.pdf

33. Jose C. Child malnutrition and the provision of water and sanitation in the Philippines. J Asia Pac Econ. 2007;12(2):125-57.

34. Radhika MS, Swetha B, Kumar NB, Krishna NB, Laxmaiah A. Dietary and nondietary determinants of nutritional status among adolescent girls and adult women in India. Ann N Y Acad Sci. 2018;1416(1):5-17.

35. Worley H. Water, sanitation, hygiene, and malnutrition in India. Population Reference Bureau. 2014.

36. Spears D, Ghosh A, Cumming O. Open defecation and childhood stunting in India: an ecological analysis of new data from 112 districts. PLoS One. 2013;8(9):e73784.

37. Fink G, Gunther I, Hill K. The effect of water and sanitation on child health: evidence from the demographic and health surveys 1986-2007. Int J Epidemiol. 2011:40(5):1196-204.

38. Todd B. An assessment of the causes of malnutrition in Ethiopia: a contribution to the formulation of a National Nutrition Strategy for Ethiopia. Washington DC: International Food Policy Research Institute; 2005. http:// www.ifpri.org/publication/assessment-causes-malnutrition-ethiopia

39. Awel AA, Lema TB, Hebo HJ. Nutritional status and associated factors among primary school adolescents of pastoral and agro-pastoral communities, MiesoWoreda, Somali region, Ethiopia: a comparative crosssectional study. J Public Health Epidemiol. 2016;8(11):297-310.

40. Isunju JB, Schwartz K, Schouten MA, Johnson WP, Dijk MP. Socio-economic aspects of improved sanitation in slums: a review. Public Health. 2011; 125(6):368-76

41. Raihan MJ, Farzana FD, Sultana S, Ahmed T. Examining the relationship between socio-economic status, WASH practices and wasting. PLoS One. 2017;12(3):e0172134.

42. Registry for international development impact evaluations. Integrated multisectoral strategy to improve girls' and women's nutrition before conception, during pregnancy and after birth in India (Swabhimaan): prospective, non-randomised controlled evaluation. Study ID: RIDIESTUDYID-58261 b2f46876. 2018. http://ridie.3ieimpact.org/index.php?r=search/ detailView\&id=485

\section{Publisher's Note}

Springer Nature remains neutral with regard to jurisdictional claims in published maps and institutional affiliations.

Ready to submit your research? Choose BMC and benefit from:

- fast, convenient online submission

- thorough peer review by experienced researchers in your field

- rapid publication on acceptance

- support for research data, including large and complex data types

- gold Open Access which fosters wider collaboration and increased citations

- maximum visibility for your research: over $100 \mathrm{M}$ website views per year

At BMC, research is always in progress.

Learn more biomedcentral.com/submissions 